Review

\title{
Development of Anticancer Drugs: From Mechanical Properties of Tumor Stiffness to cytoskeleton-targeting natural products
}

\author{
Xiaoye Liu'1,2, , Hongwei $\mathrm{Xu}^{1}$, Yuting Feng ${ }^{1}$ and Xiaolin Hou ${ }^{2, *}$ \\ 1 Beijing Traditional Chinese Veterinary Engineering Center and Beijing Key Laboratory of Traditional Chi- \\ nese Veterinary Medicine, Beijing University of Agriculture, No.7 Beinong Road, Changping, Beijing \\ 102206, China. \\ 2 Department of Mechanics and Engineering Science, College of Engineering, Peking University, No.5 Yi- \\ heyuan Road, Haidian, Beijing 100871, China. \\ * Correspondence: xiaoyeliu@pku.edu.cn; hxlsx@163.com
}

Simple Summary: Tumor has the classical mechanical properties due to the dynamics of tumor cytoskeleton and stiffness. Anticancer drugs that focused on cytoskeleton-targeting natural products are summarized in this review for future development and discovery of the new anticancer drugs that based on the mechanical mechanisms of tumor stiffness.

\begin{abstract}
Mechanical properties of tumor cytoskeleton are extremely vital for any phases of cancer, especially in tumor invasion and metastasis. However, in current category of anticancer drugs, the cytoskeleton-targeting drugs are limited and its role in tumor progression is unclear. Here, we present the mechanical characteristics of tumor stiffness are tightly regulated by cancer cytoskeleton including actin filaments and microtubule during tumor initiation, growth and metastasis, and review the natural drugs that target cancer cytoskeleton. We define cytoskeleton dynamics as target mechanisms for anticancer drug, and summary the plant, microbial and marine sources of natural products. Furthermore, the material approaches to active cancer mechanics are supplied in this review. We aim to promote the development of anticancer drugs that target tumor mechanics by using those material approaches in future and find its pharmacological application.
\end{abstract}

Keywords: anticancer drugs; mechanical microenvironment; tumor stiffness; cytoskeleton dynamics; material approaches

\section{Introduction}

Cancer is a malignant tumor that originates from epithelium. Mechanical regulation has a significant role in both epithelial cells and cancer cells on their physiological and pathological progressions [1,2]. The mechanical properties of cancer cells are initiated by their mechanical microenvironment including but not limited to the stiffness of the surrounding extracellular matrix (ECM) substrates and further regulated the tumor stiffness $[3,4]$. Most important, the mechanical stiffness plays a critical role in cancer progression. For instance, in breast cancer, the increased stiffness of ECM drives tumorigenic phenotype in mammary epithelium [1]. The tumor stiffening are occurred in metastatic colorectal cancer [5]. In fact, cancer cytoskeleton that depends on actin filaments and microtubules to regulate the mechanical properties of tumor tissue plays a key role in homeostasis, morphogenesis and cancer metastasis [6]. Thus, assessing the mechanical characteristics of tumor by cytoskeletal dynamics of cancer cells during cancer progression acts as a good indicator in cancer diagnostics, prophylactics, therapeutics, especially in drug development [7-10].

However, the efforts on the discovery of anticancer drugs most limited in those cytotoxic drugs to induce turmorshrinkage [11,12]. In addition, the unclear mechanism 
action of the anticancer drugs and no detailed evaluated manner may prevent the application in clinical trial. Moreover, the focus on cytoskeleton-targeting natural products sourced anticancer drugs is important and relevant to translational therapies in cancer disease from tumor mechanical mechanisms attention to its pharmacological application. Therefore, the mechanical regulations of cytoskeleton-targeting natural anticancer drugs should be illustrated before clinical therapy.

At present, the underlying mechanisms among mechanical stiffness, cancer cell and cytoskeleton are clear $[6,7,13]$, while the unknow event is that the relationship between mechanical stiffness and anticancer drug (Figure 1A). Since anticancer drugs have the direct inhibition on cancer cells and cytoskeleton dynamics $[10,14,15]$, there must be some connections between the two. Thus, the mechanical mechanisms of tumor progressions and cytoskeleton dynamics should be clarified. As a matter of fact, the cytoskeleton dynamics occur in the polymerization and depolymerization of microfilaments and microtubules and mechanical stiffness response to cancer cytoskeleton $[6,16]$. Cancer cytoskeletons promote the tumor initiation, growth and tumor metastasis is displayed in Figure 1B. Yet, more detailed mechanisms of the mechanical properties of tumor tissue are urgent to reveal before the development of anticancer agents for the guidance of anticancer strategies.

Here, we firstly summarize cytoskeleton-associated mechanical stuffs during tumor progressions involving the mechanical stiffness that tumor microenvironment of the surrounding ECM substrates and tumor tissue. We define cytoskeleton dynamics as target mechanisms for anticancer and review present cytoskeleton-targeting natural products. Finally, we also provide the overview of the 2D and 3D substrate materials that used to active tumor mechanics, which can apply in drug discovery and the research on its mode actions.

\section{Mechanical microenvironment of tumor tissue}

Tumor microenvironment are complex and compose of ECM, which surrounds with both normal epithelial cells and activated cancer cells [17]. The mechanical properties of tumor microenvironment refer to the ECM stiffness and have been implicated that matrix stiffness influenced cancer behaviors. In addition, cellular behaviors are altered with the changes in tissue stiffness to facilitate disease progression [18,19]. In fact, the emerging researches have revealed that the ECM stiffness were different far away between normal epithelial cells and cancer cells [20,21]. The stiffness of ECM substrates that surrounding of the normal epithelial cells are $\sim 150 \mathrm{~Pa}$, while breast cancer cells are showing an increased ECM stiffness of $\sim 4-5 \mathrm{kPa}$ as shown in Figure 2A [22]. Indeed, mechanical cues such as increased ECM stiffness promote the progression of cancer cells to form tumor tissue [1]. In addition, cancer cells spread less and have shorter actin filaments on soft substrates, while exhibition of a polarized morphology and show stress fibers, moreover, cells have higher proliferation on matrix rigidity than softer one (Figure 2B) [23]. As a response, cancer cytoskeletons including microfilaments and microtubules are participated in the different shapes and grades of cancer cells [6]. The connections of cytoskeleton and ECM are displayed in Figure 2B, the actin dynamics regulated by G-actin and Factin, the myosin II and integrins linked ECM substrates are all contribute to mechanical stiffness [24-26]. And various reports have revealed that microtubules and microfilaments on mechanical properties of cancer cells, between them the crosslinker plays an action role $[27,28]$.

\section{The inner mechanical stiffness of tumor tissue}

Tumor tissue occurs and survives in a three-dimensional (3D) microenvironment. Precisely, any multicellular tissue has a 3D shape. Mechanical integrity and biological function maintain within the special tissue volume. Investigation of the mechanical cues in tumor $3 \mathrm{D}$ structure is better for the anticancer therapy in vivo. Fortunately, materials 
and instruments are available to do the depth research of multicellular system in 3D environments by 3D hydrogels [4,29]. Therefore, the inner mechanical stiffness of tumor tissue is uncovered, and also reveals the tumor development by physical characteristics of individual cells. As exhibited in Figure $2 \mathrm{C}$, the tumor tissue divides into core to periphery parts. The intratumor stress and cancer stiffness decreases from core to periphery cells, while the volumes of cancer cells are increase [4,29]. In addition, the cytoskeleton between core cells and periphery cells were significantly different [30]. Most important is that the periphery cells have abundant stress fibers, which tend to facilitate tumor invasion [4]. Take it together, the mechanical stiffness regulated by cytoskeleton of cancer cells and tumor tissue are key factors and indicators for controlling tumor progression, which should be best targets for the development of anticancer drugs.

Anticancer drugs origin from cytoskeleton-targeting natural products

In the cancer progression phase, especially in solid cancers, more than $90 \%$ of mortality causes by tumor invasion and metastasis [31,32], anticancer drugs that targeting cytoskeleton are one of the most effective therapy to control tumor invasion and metastasis [33]. Cytoskeleton-targeting natural products mainly origin from plant, microbial and marine sources [32], we list the classical compounds to illustrate the cytoskeleton function during tumor mechanics. As showed in Figure 3A, cucurbitacins, taxol and vinblastine are the natural products from plants; chondramides and cytochalasins derive from microbial source; gediamolides, jasplakinolide and latrunculins are the member from marine source. Among these natural compounds, taxol and vinblastine are targeting microtubule, while the others are all targeting microfilaments. The different functional manners of cytoskeleton-targeting anticancer agents to hijack cancer cytoskeleton, are detailed in Table 1 and further discussed below.

\section{Actin-Targeting Anticancer Drugs}

Actin dynamics are critical mechanical component involved in cancer growth, invasion and migration [24,27]. Drugs that targeting actin can be categorized as the drugs that destabilize the actin filaments and the agents that stabilize actin cytoskeleton [10]. As shown in Figure 3B, the processes of actin dynamics are tightly regulated by two actin members, a free monomer called G-actin (spherical actin) or as part of linear polymer microfilaments called F-actin (filamentous actin). F-actin can also be described as microfilaments. The two parallel F-actin chains must be rotated by 166 degrees to be on top of each other properly. This produces the double helix structure of the micro filaments found in the cytoskeleton. The diameter of the microfilament is about $7 \mathrm{~nm}$, and the helix repeats every $37 \mathrm{~nm}$. Each actin molecule binds to either adenosine triphosphate (ATP) or adenosine diphosphate (ADP) molecules, which are associated with $\mathrm{Mg}^{2+}$ cations. Compared with all possible combinations, the most common actin forms are ATP-G-actin and ADPF-actin. The actin depolymerization occurs on (-) end of F-actin, while polymerization on $(+)$ end.

\section{Actin-Destabilizing Drugs}

Cytochalasins family mostly derive from the species of fungi (more than $60 \%$ ). The size of the macrocyclic ring and the substituent of the perhydroisoindolyl-

1-one residue at the C-3 position are used to classify the cytochalasin subgroup, the chemical structure of cytochalasin D is shown in Figure 4. Cytochalasins are the actin destabilizers and inhibit actin filaments by binding to its (+) end. Cytochalasins can be used for the treatment of gastric, breast and colorectal cancers (Table 1). In addition, cytochalasin E can be used as the adjuvant of bortezomib to increase the drug sensitivity of human lung cancer A549 cells via inhibition of autophagy [34]. Recently, synthesis technologies further expand the diverse functional use of cytochalasins [35].

Gediamolides are actin destabilizers that interfering with actin filaments and derived from marine sponges. By culturing cancer cell lines in a 3D environment, reports show that gediamolide $\mathrm{H}$ (Figure 4) affects the aggressive of tumor cells and inhibits migration and invasion of Hs578T cells via modifications in actin cytoskeleton [36] 
Latrunculins are the actin-targeting agents, also derived from marine sponges. Latrunculins lead actin depolymerization by the sequestration of G-actin monomers The chemical structure of latrunculin A is shown in Figure 4, and many marine source macrolides have the similar functions of disrupting the actin cytoskeleton [37]. The main drug therapy of latrunculins is inhibiting the invasion of tumor cells [38,39].

\section{Actin-Stabilizing Drugs}

Actin stabilizing drugs discussed in this work are the typical natural compounds that have the abilities of stabilizing actin cytoskeleton, triggering deregulated polymerization, leading monomer depletion and accumulations of large filament aggregates. Targeting actin stabilizing also has the better

Cucurbitacins, the family of Cucurbitaceae belongs to the plant natural products is reported that has the significant function of stabilized actin cytoskeleton. Cucurbitacin E can bind to F-actin and form a covalent bond at residue Cys257 [40]. Therefore, cucurbitacin $\mathrm{E}$ is used for inhibiting the breast tumor and lung cancer metastasis by suppressing the cell migration and invasion (Table 1) [41,42].

Chondramides are the cyclodepsipeptides that derived from the myxobacterium Chondromycescrocatus crocatus [43]. Chodramides bind to F-actin to stabilize the actin cytoskeleton. Chondramides used as the migrastatic drug to inhibit the invasion of cancer cells [44].

Jasplakinolide is an actin stabilizer that come from marine sponges. The function of jasplakinolide promote actin polymerization and its binding to actin filament is competitive with phalloidin [45], which can inhibit lung metastases [14].

\section{Microtubule-Targeting Drugs}

Microtubule targeting agents for cancer therapy are important therapeutic target in tumor cells $[46,47]$. Before drugs that target microtubules work, it is necessary to understand the formation process of microtubules. Microtubule is a heterodimer formed by the polymerization of two protein molecules, namely $\alpha$-, $\beta$-tubulin molecules. As shown in Figure 3C, in order to form microtubules, the dimer of $\alpha$ - and $\beta$-tubulin binds to GTP and assembles to the microtubule in the GTP-bound state. The $\beta$-tubulin subunit is exposed at the positive end of the microtubule, and the $\alpha$-tubulin subunit is exposed at the negative end. After the dimer is incorporated into the microtubules, the GTP molecules bound to the $\beta$-tubulin subunits are finally hydrolyzed into GDP through contact between the dimers along the microtubule protofilaments. Whether the $\beta$-tubulin member of the tubulin dimer binds to GTP or GDP will affect the stability of the dimer in the microtubule. Dimers bound to GTP tend to assemble into microtubules, while dimers bound to GDP tend to split. Therefore, this GTP cycle is essential for the dynamic instability of microtubules. Thus, microtubules are become the major targets to development of anticancer drugs, they display the most effective drugs especially in the therapy of solid tumors [48-50]. The two classical microtubule-targeted natural drugs are introduced following.

Taxol (Paclitaxel) is one of classical microtubule-stabilizing agents that isolates from natural plant, the stem bark of the western yew, Taxus brevifolia Nutt [51]. The structure of paclitaxel shows that it belongs to diterpene with a tetracyclic 17 carbon frame and 11 stereocenters (Figure 4). The stabilized function of paclitaxel on microtubule is that it can preferentially binds to the $\beta$-subunit of tubulin, then make tubulin and tubulin dimer lose dynamic equilibrium, finally inducing and promoting microtubule polymerization, assembly and prevent depolymerization [52]. Paclitaxel exhibits a potential broad-spectrum anticancer activity, especially in the therapy of ovarian cancer, breast cancer and nonsmall cell lung cancer [52]. In addition, Paclitaxel also play a large role in tumor immunity [53].

Vinblastine is completely opposite to paclitaxel in the anticancer mechanism used as the microtubule-destabilizing drug [54]. This product mainly inhibits the polymerization of tubulin, and hinders the formation of spindle microtubules, so that nuclear fission stops at the middle stage. Vinblastine effective against malignant lymphoma, choriocarcinoma 
and testicular neoplasms, as well as lung cancer, breast cancer, ovarian cancer and mononuclear leukemia $[55,56]$.

Cytoskeleton-targeting drugs have been discontinued due to significant toxicity, most of them are caused by the nonspecificity of the target. Although an appropriate protein delivery system can be conjugated to drugs to potent therapeutic benefits, thereby delivering highly specific treatments of cytoskeleton-targeting drugs to neoplastic tissue, the other developed manner need be used in future. Indeed, the cytoskeleton is much difference between normal cells and cancer cells as our summarized (Figure 2 and 3), which further trigger different mechanical behaviors. Therefore, illustration of cytoskeleton modulated mechanics in cancer cells by using modern advanced material approaches is a prerequisite for future development of anticancer drugs.

\section{Material approaches on anticancer drug in future}

In cellular mechanical field, the approaches including 2D and 3D materials are employed for the study of cellular dynamics and mechanics to underly the physiological and pathological processes of cells $[29,57]$. Therefore, we overview majority material approaches in Figure 5, and aim to inspire the mechanical research topics and drug targets of anticancer therapy in future. The 2D flat substrates are usually used for recover the flexible substrate environment of cell growth due to the Young's moduli of the surrounding substrates in vivo mostly are less than $100 \mathrm{kPa}$ [58]. Thus, the mechanical mechanisms of ECM stiffness on the cancer cell growth and initiation, even the differences from normal cells will be clarified by using the $2 \mathrm{D}$ flat substrates. Furthermore, the anticancer drugs that target tumor cell proliferation and initiation can be screened by this system.

Actually, the tissues have a variety of topological forms, such as coiled structure of small intestine. The microfabricated substrate with topographical patterns can achieve it. By using this material, how tissue structure induces tumorigenesis and the progression of tumor stiffness in different histological structures will be understand. The anticancer drugs that target cancer cell invasion, growth and metastasis can be well developed by thus. For the 3D-structure of tumor, 3D hydrogels provide better platform to investigate how mechanical environment modulates tumor stiffness and further affect tumor metastasis. Additionally, the platform is more conducive to screening out drugs for tumor control and prevention and control of tumor growth and migration. Take it together, we believe that material approaches to active the mechanics of tumor tissue can be well applied in discovery of anticancer drug in future.

\section{Conclusion}

In summary, mechanical properties of tumor stiffness that modulated by cancer cytoskeleton are critical for tumor progression. The anticancer drugs from cytoskeleton-targeting natural products that directly disturb the cytoskeleton dynamics are worth to develop. Furthermore, the material approaches to active cancer mechanics that supplied in this review will provide an in vitro platform for the investigation of anticancer drugs that target tumor mechanics and find its pharmacological application.

\section{Funding}

This work was supported by Open Fund of Shenzhen Institute of Synthetic Biology (Grant no. DWKF20190002)

\section{Author contributions}

X.L., X.H., H.X. and Y.F. wrote and edited the manuscript. X.L. draw the figures. H.X. and Y.F. prepared the table. X.L., X.L. and H.X. did the data collection. All authors read and approved the manuscript.

\section{Conflicts of interest}

The authors declare no conflicts of interest. 


\subsection{Figures, Tables and Schemes}

A

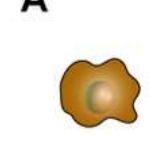

\section{Cancer cell}

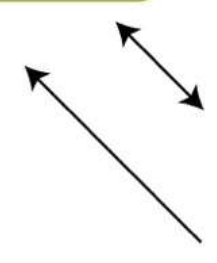

Cytoskeleton dynamics

\section{Anticancer drug}

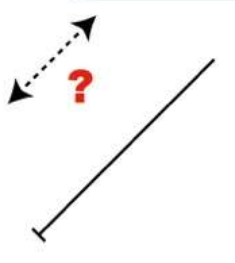

B
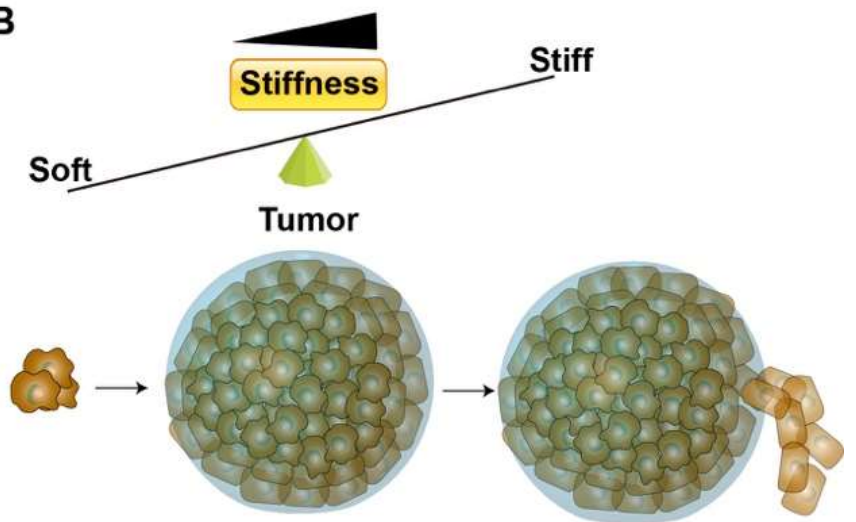

Tumor initiation Tumor growth

Tumor metastasis
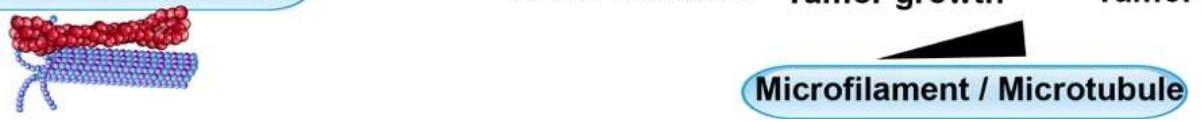

Figure 1. The relationship between cytoskeleton regulated tumor stiffness and anticancer drugs that target at cytoskeleton dynamics.

(A) Anticancer drugs that target cytoskeleton dynamics are in unknow function on tumor stiffness. Anticancer drugs can inhibit cancer cells and disrupt cytoskeleton dynamics and both cancer cell and its cytoskeleton dynamics are modulated by mechanical stiffness, while the relationship between anticancer drugs and mechanical stiffness is unknow. Actually, cytoskeleton dynamics promote the growth change of cancer cells. Mechanical stiffness and cancer cells or cytoskeleton dynamics have regulated each other.

(B) Tumor stiffness and cancer cytoskeleton are regulated with tumor progression. Cytoskeleton of cancer cells including microfilament and microtubule are increase as well as tissue stiffness from tumor initiation, tumor growth to tumor metastasis.

Table 1. Anticancer drugs that target cytoskeleton dynamics

\begin{tabular}{|c|c|c|c|c|c|c|c|}
\hline Origin & & Drug & Target & Activity & Models & Cancer & Refs \\
\hline \multirow[t]{2}{*}{ Plant } & Cucurbitaceae & $\begin{array}{l}\text { Cucurbitacin } \\
\text { E }\end{array}$ & $\begin{array}{l}\text { Actin } \\
\text { stabilizer }\end{array}$ & $\begin{array}{l}\text { Inhibition of the } \\
\text { depolymerizatio } \\
\mathrm{n} \text { of actin } \\
\text { filaments }\end{array}$ & $\begin{array}{l}4 \mathrm{~T} 1 \\
\text { and } \\
\text { MDA- } \\
\text { MB- } \\
231 \\
\text { breast } \\
\text { cancer } \\
\text { cells }\end{array}$ & $\begin{array}{l}\text { Breast cancer, } \\
\text { lung cancer }\end{array}$ & $\begin{array}{l}{[42,59,} \\
60]\end{array}$ \\
\hline & Taxus chinensis & Taxol & $\begin{array}{l}\text { Microtubule } \\
\text { stabilizer }\end{array}$ & $\begin{array}{l}\text { It can promote } \\
\text { microtubule } \\
\text { polymerization, } \\
\text { assembly and } \\
\text { prevent } \\
\text { depolymerizatio } \\
\mathrm{n}\end{array}$ & $\begin{array}{l}\text { Breast } \\
\text { cancer } \\
\text { cell et } \\
\text { al. }\end{array}$ & $\begin{array}{l}\text { Ovarian cancer, } \\
\text { breast cancer, } \\
\text { some neck cancer } \\
\text { and non-small cell } \\
\text { lung cancer }\end{array}$ & $\begin{array}{l}{[52,61,} \\
62]\end{array}$ \\
\hline
\end{tabular}




\begin{tabular}{|c|c|c|c|c|c|c|c|}
\hline & Apocynaceae & Vinblastine & $\begin{array}{l}\text { Microtubule } \\
\text { destabilizer }\end{array}$ & $\begin{array}{l}\text { Depolymerizati } \\
\text { on of } \\
\text { microtubule }\end{array}$ & $\begin{array}{l}\text { Nonsm } \\
\text { all-cell } \\
\text { subtype }\end{array}$ & $\begin{array}{l}\text { Malignant } \\
\text { lymphoma, } \\
\text { choriocarcinoma, } \\
\text { lung cancer, } \\
\text { breast cancer, } \\
\text { ovarian cancer } \\
\text { and mononuclear } \\
\text { leukemia. }\end{array}$ & [54-56] \\
\hline \multirow[t]{2}{*}{$\begin{array}{l}\text { Microb } \\
\mathrm{e}\end{array}$} & Fungi & Cytochalasins & $\begin{array}{l}\text { Actin } \\
\text { destabilizer }\end{array}$ & $\begin{array}{l}\text { Direct severing } \\
\text { of actin } \\
\text { filaments, } \\
\text { inhibition of } \\
\text { actin subunit } \\
\text { polymerization }\end{array}$ & $\begin{array}{l}\text { AGS, } \\
\text { CT26 } \\
\text { colorec } \\
\text { tal } \\
\text { carcino } \\
\text { ma } \\
\text { cells }\end{array}$ & $\begin{array}{l}\text { Gastric cancer; } \\
\text { breast carcer and } \\
\text { colorectal cancer }\end{array}$ & {$[32,63]$} \\
\hline & $\begin{array}{l}\text { Myxobacterium } \\
\text { Chondromycescrocat } \\
\text { us crocatus }\end{array}$ & Chondramides & $\begin{array}{l}\text { Actin } \\
\text { stabilizer }\end{array}$ & $\begin{array}{l}\text { Anti- } \\
\text { invasiveness; } \\
\text { Anti- } \\
\text { phosphorylation } \\
\text { of MLC; Anti- } \\
\text { contractility }\end{array}$ & $\begin{array}{l}\text { MDA- } \\
\text { MB- } \\
231 \\
\text { cells }\end{array}$ & $\begin{array}{l}\text { Breast cancer, } \\
\text { lung cancer }\end{array}$ & {$[43,44]$} \\
\hline \multirow[t]{3}{*}{ Marine } & $\begin{array}{l}\text { Brazilian sponge } \\
\text { Geodia } \\
\text { corticostylifera }\end{array}$ & Gediamolides & $\begin{array}{l}\text { Actin } \\
\text { destabilizer }\end{array}$ & $\begin{array}{l}30 \% \text { decrease } \\
\text { on invasive } \\
\text { behavior of } \\
\text { Hs578T cells. }\end{array}$ & $\begin{array}{l}\text { MCF-7 } \\
\text { and } \\
\text { Hs578 } \\
\text { T cells }\end{array}$ & Breast cancer & {$[36]$} \\
\hline & Marine sponges & Jasplakinolide & $\begin{array}{l}\text { Actin } \\
\text { stabilizer }\end{array}$ & $\begin{array}{l}\text { It promotes } \\
\text { actin } \\
\text { polymerization } \\
\text { and stabilizes } \\
\text { actin filaments. } \\
\text { Its binding to F- } \\
\text { actin is } \\
\text { competitive } \\
\text { with phalloidin. }\end{array}$ & - & Lung cancer & {$[45]$} \\
\hline & & Latrunculins & $\begin{array}{l}\text { Actin } \\
\text { destabilizer }\end{array}$ & $\begin{array}{l}\text { G-actin; } \\
\text { interaction } \\
\text { with thymosin } \\
\text { b4; }\end{array}$ & $\begin{array}{l}\text { AMDC } \\
-\mathrm{S} \text { and }\end{array}$ & $\begin{array}{l}\text { Breast cancer and } \\
\text { gastric cancer }\end{array}$ & $\begin{array}{l}{[38,39,} \\
64]\end{array}$ \\
\hline
\end{tabular}




\begin{tabular}{lll}
\hline & $>95 \%$ inhibition & AMDC \\
& of & AS \\
& invasiveness at & cell \\
Lines; & MDA- & MB- \\
& $100 \mathrm{ng} / \mathrm{mL} ; \quad$ Anti- & 231 \\
& invasiveness & cells; \\
& & MKN4 \\
& & and \\
& & NUGC- \\
& & 4 cells \\
\hline
\end{tabular}

Note:

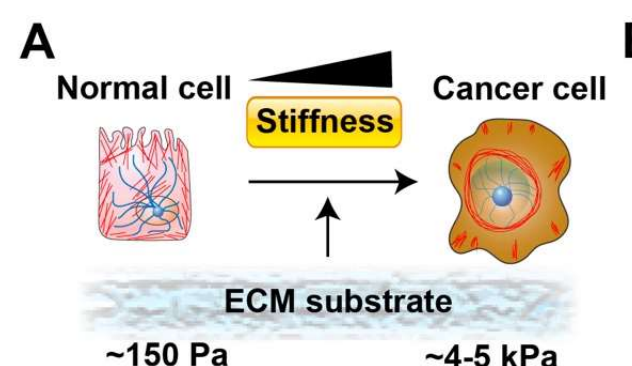

C

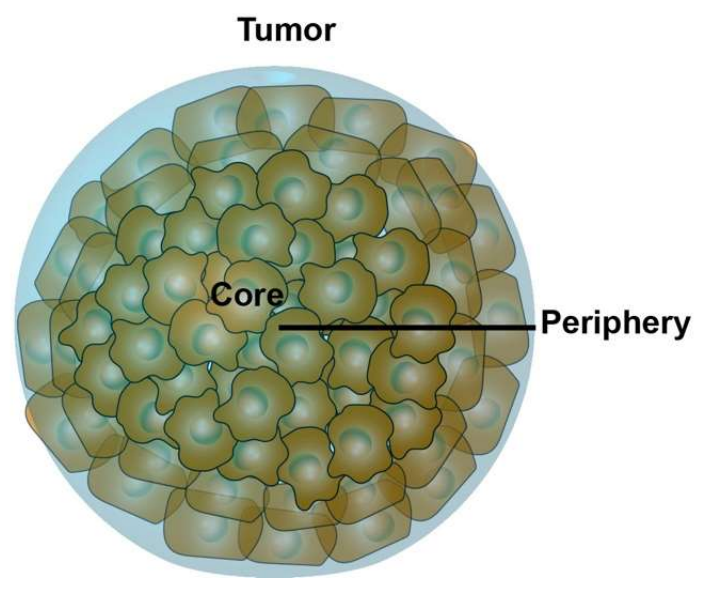

B
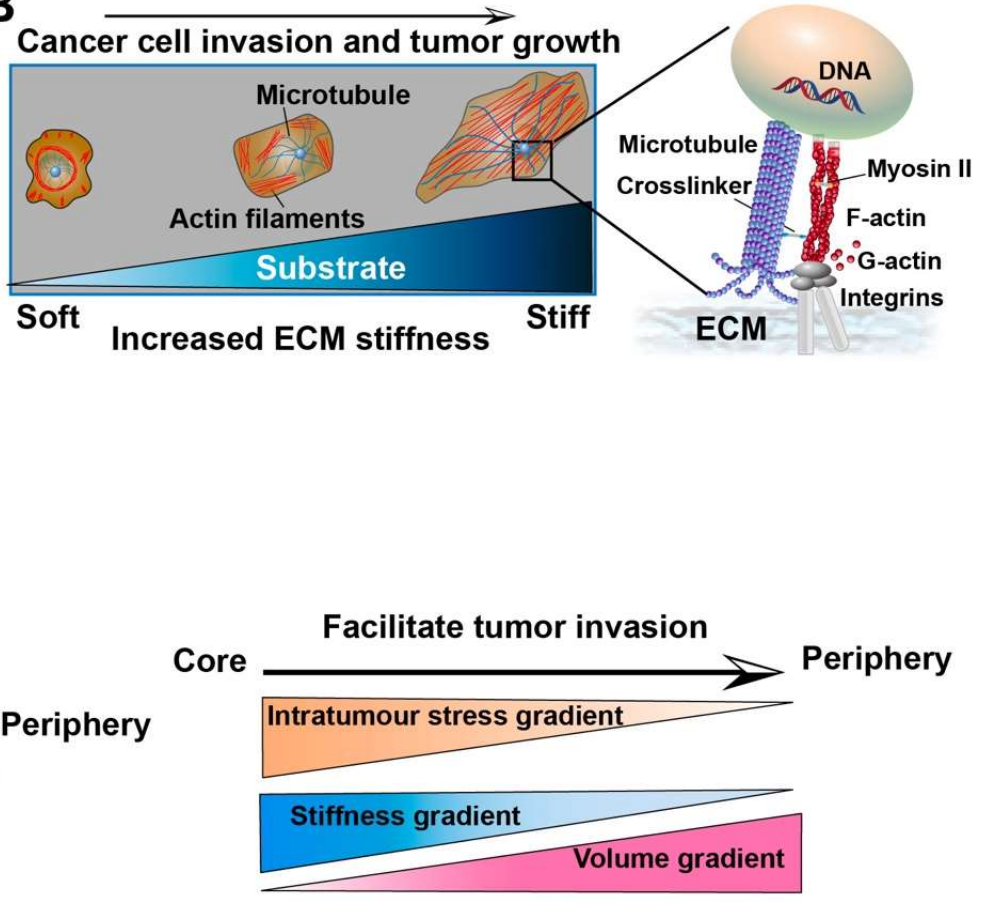

Figure 2. Mechanical microenvironment of tumor tissue is critical for tumor progression.

(A) The mechanical regulations between extracellular matrix (ECM) substrates and cancer cells. ECM stiffness surrounds normal cell are lower than cancer cell. The stiffness of ECM substrates on breast epithelial cells and cancer cells are $~ 150$ $\mathrm{Pa}$ and $\sim 4-5 \mathrm{kPa}$, respectively.

(B) Cancer cell invasion and tumor growth are fast following with the increased ECM stiffness, which promotes the cancer cells form tumor tissue [23]. Cytoskeleton dynamics of cancer cells including actin and microtubule dynamics are crosslink with each other.

(C) Tumor stiffness modulates tumor progression. The intratumour stress gradient reduces from core to periphery and thus leads cell volume turn bigger and tumor stiffness decrease, which together facilitate tumor cell invasion [4]. 


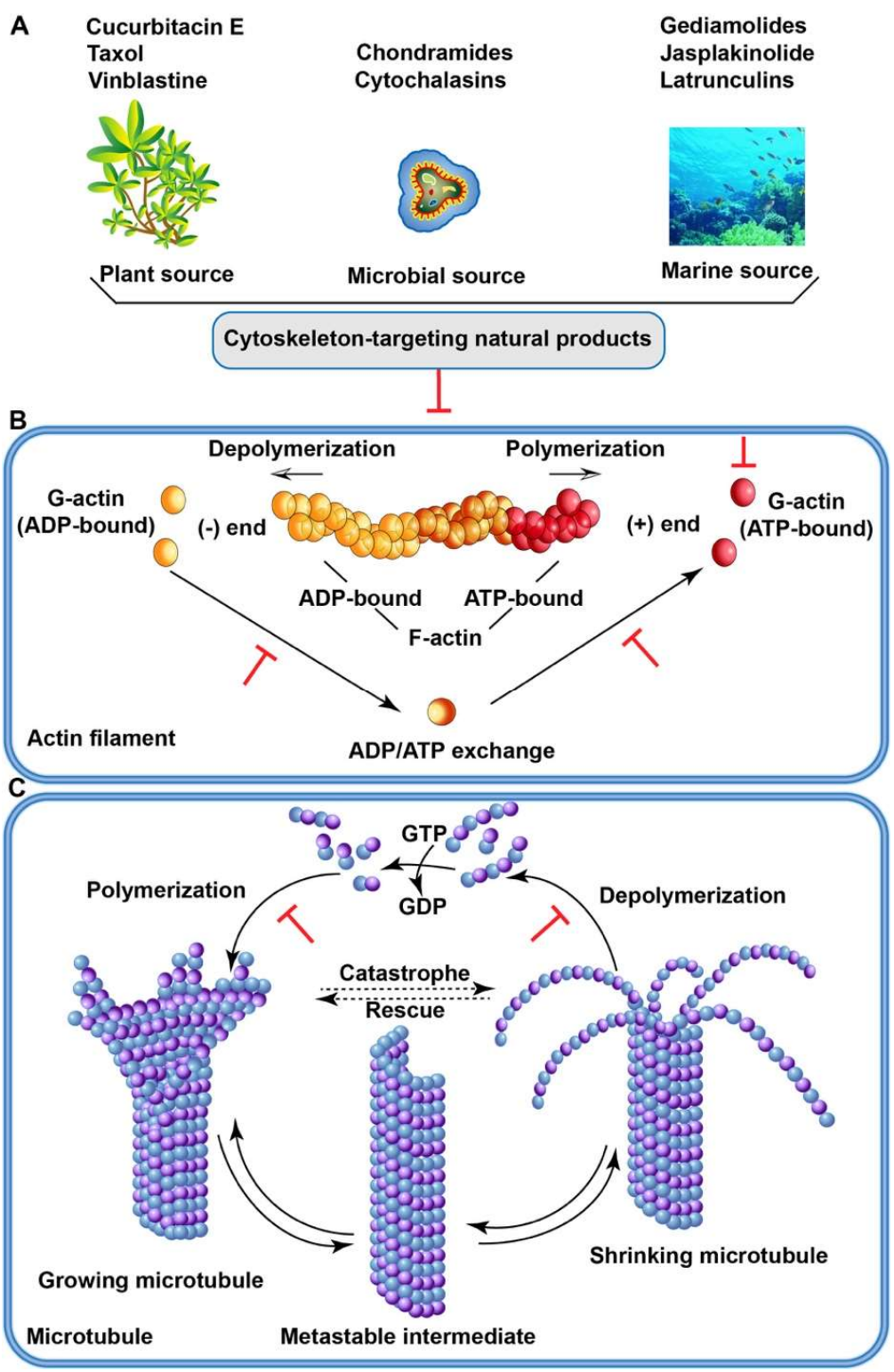

Figure 3. Functional action of cytoskeleton-targeting natural products.

(A) Cytoskeleton-targeting natural products mainly origin from plant, microbial and marine source. Plant source: cucurbitacin E, taxol and vinblastine; Microbial source: chondramides and cytochalasins; Marine source: gediamolides, jasplakinolide and latrunculins.

(B and C) The mode action of anticancer drugs on cancer cytoskeleton of actin filaments and microtubules. The cytoskeleton dynamic process of depolymerization and polymerization are in black arrows, while the drug targets were highlight in red. 


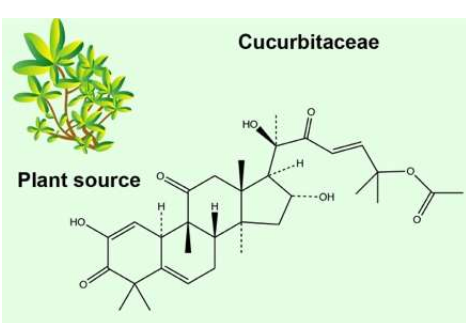

Cucurbitacin E
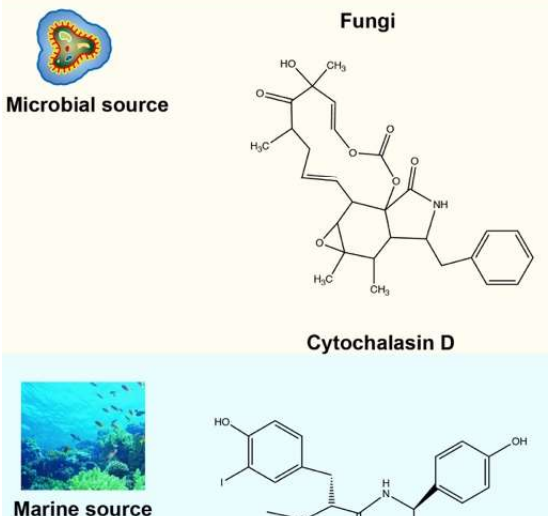

Marine source
Cytochalasin D

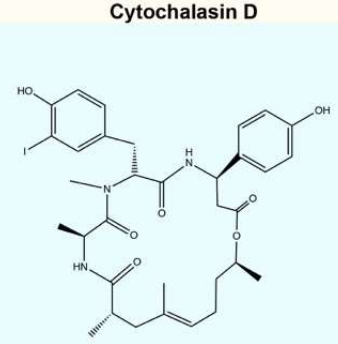

Gediamolide H
Taxus chinensis

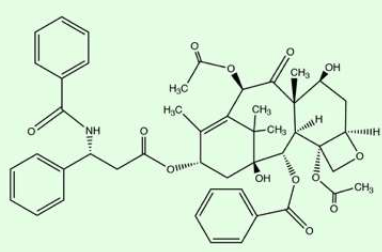

Taxol

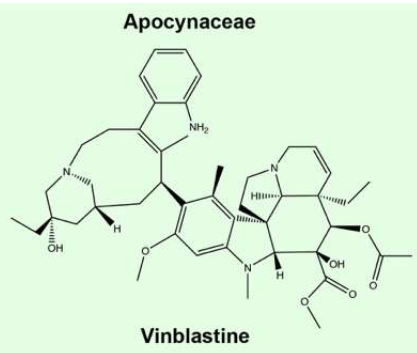

myxobacterium Chondromycescrocatus crocatus

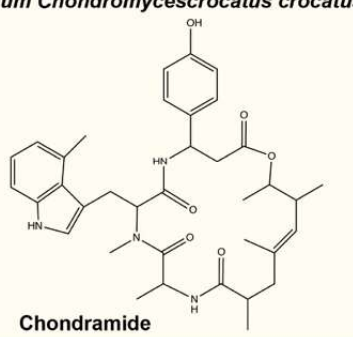

Marine sponges

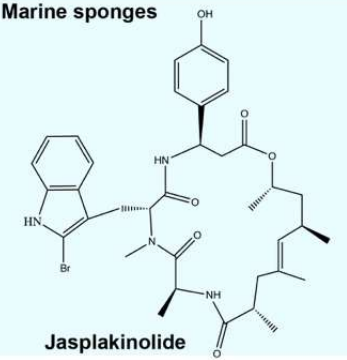

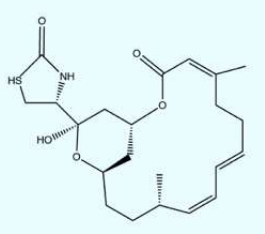

Latrunculin A

Figure 4. The chemical structures of natural drugs that target of cancer cytoskeleton.

Cytoskeleton-targeting natural products mainly origin from plant source (e.g., cucurbitacin E, taxol and vinblastine), microbial sources (e.g., chondramides and cytochalasins) and marine sources (e.g., gediamolides, jasplakinolide and latrunculins). 


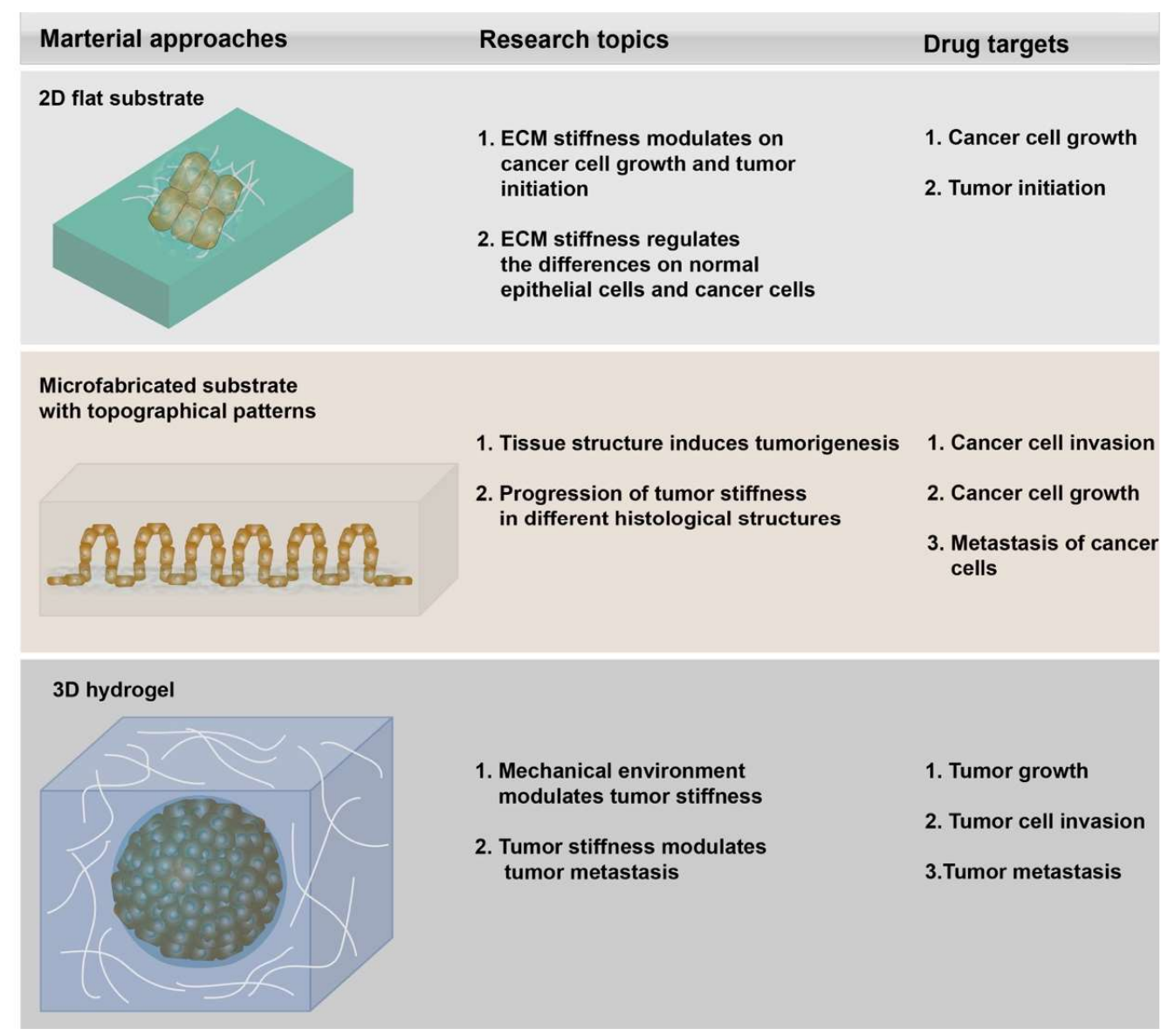

Figure 5. Material approaches to active tumor mechanics to develop anticancer drug in future. The material approaches to active tumor mechanics are including 2D flat substrates, microfabricated substrate with topographical patterns and 3D hydrogels. The research topics exhibited on mechanical stiffness of tumor and cancer diseases are showed. Targets of candidate anticancer drugs are also displayed. 


\section{References}

1. Stowers, R.S.; Shcherbina, A.; Israeli, J.; Gruber, J.J.; Chang, J.; Nam, S.; Rabiee, A.; Teruel, M.N.; Snyder, M.P.; Kundaje, A.; et al. Matrix stiffness induces a tumorigenic phenotype in mammary epithelium through changes in chromatin accessibility. Nat Biomed Eng 2019, 3, 1009-1019.

2. Pinheiro, D.; Bellaiche, Y. Mechanical force-driven adherens junction remodeling and epithelial dynamics. Dev Cell 2018, 47, 3-19.

3. Guo, M.; Pegoraro, A.F.; Mao, A.; Zhou, E.H.; Arany, P.R.; Han, Y.; Burnette, D.T.; Jensen, M.H.; Kasza, K.E.; Moore, J.R.; et al. Cell volume change through water efflux impacts cell stiffness and stem cell fate. Proc Natl Acad Sci U S A 2017, 114, E8618-e8627.

4. Han, Y.L.; Pegoraro, A.F.; Li, H.; Li, K.; Yuan, Y.; Xu, G.; Gu, Z.; Sun, J.; Hao, Y.; Gupta, S.K.; et al. Cell swelling, softening and invasion in a three-dimensional breast cancer model. Nat Phys 2019, 16, 101-108.

5. Zhang, J.; Reinhart-King, C.A. Targeting tissue stiffness in metastasis: mechanomedicine improves cancer therapy. Cancer Cell 2020, 37, 754-755.

6. Pachenari, M.; Seyedpour, S.M.; Janmaleki, M.; Babazadeh Shayan, S.; Taranejoo, S.; Hosseinkhani, H. Mechanical properties of cancer cytoskeleton depend on actin filaments to microtubules content: investigating different grades of colon cancer cell lines. J Biomech 2014, 47, 373-379.

7. Pokorný, J.; Vedruccio, C.; Cifra, M.; Kučera, O. Cancer physics: diagnostics based on damped cellular elastoelectrical vibrations in microtubules. Eur Biophys J 2011, 40, 747-759.

8. Stehn, J.R.; Haass, N.K.; Bonello, T.; Desouza, M.; Kottyan, G.; Treutlein, H.; Zeng, J.; Nascimento, P.R.; Sequeira, V.B.; Butler, T.L.; et al. A novel class of anticancer compounds targets the actin cytoskeleton in tumor cells. Cancer Res 2013, 73, 51695182.

9. $\quad$ Foerster, F.; Braig, S.; Moser, C.; Kubisch, R.; Busse, J.; Wagner, E.; Schmoeckel, E.; Mayr, D.; Schmitt, S.; Huettel, S.; et al. Targeting the actin cytoskeleton: selective antitumor action via trapping PKCvarepsilon. Cell Death Dis 2014, 5, e1398.

10. Yu, Q.; Zhang, B.; Zhang, Y.M.; Liu, Y.H.; Liu, Y. Actin cytoskeleton-disrupting and magnetic field-responsive multivalent supramolecular assemblies for efficient cancer therapy. ACS Appl Mater Interfaces 2020, 12, 13709-13717.

11. Pérez-Herrero, E.; Fernández-Medarde, A. Advanced targeted therapies in cancer: drug nanocarriers, the future of chemotherapy. Eur J Pharm Biopharm 2015, 93, 52-79.

12. Zugazagoitia, J.; Guedes, C.; Ponce, S.; Ferrer, I.; Molina-Pinelo, S.; Paz-Ares, L. Current challenges in cancer treatment. Clin Ther 2016, 38, 1551-1566.

13. Calzado-Martin, A.; Encinar, M.; Tamayo, J.; Calleja, M.; San Paulo, A. Effect of actin organization on the stiffness of living breast cancer cells revealed by peak-force modulation atomic force, icroscopy. ACS Nano 2016, 10, 3365-3374.

14. Foerster, F.; Braig, S.; Chen, T.; Altmann, K.H.; Vollmar, A.M. Pharmacological characterization of actin-binding (-)doliculide. Bioorg Med Chem 2014, 22, 5117-5122.

15. Yu, Q.; Zhang, B.; Li, J.; Li, M. The design of peptide-grafted graphene oxide targeting the actin cytoskeleton for efficient cancer therapy. Chem Commun (Camb) 2017, 53, 11433-11436.

16. Padilla-Rodriguez, M.; Parker, S.S.; Adams, D.G.; Westerling, T.; Puleo, J.I.; Watson, A.W.; Hill, S.M.; Noon, M.; Gaudin, R.; Aaron, J.; et al. The actin cytoskeletal architecture of estrogen receptor positive breast cancer cells suppresses invasion. Nat Commun 2018, 9, 2980.

17. Malik, R.; Lelkes, P.I.; Cukierman, E. Biomechanical and biochemical remodeling of stromal extracellular matrix in cancer. Trends Biotechnol 2015, 33, 230-236.

18. Lampi, M.C.; Reinhart-King, C.A. Targeting extracellular matrix stiffness to attenuate disease: From molecular mechanisms to clinical trials. Sci Transl Med 2018, 10, eaao0475.

19. Giussani, M.; Merlino, G.; Cappelletti, V.; Tagliabue, E.; Daidone, M.G. Tumor-extracellular matrix interactions: Identification of tools associated with breast cancer progression. Semin Cancer Biol 2015, 35, 3-10.

20. Discher, D.E.; Janmey, P.; Wang, Y.L. Tissue cells feel and respond to the stiffness of their substrate. Science 2005, 310, 11391143. Janmey, P.A.; Fletcher, D.A.; Reinhart-King, C.A. Stiffness sensing by cells. Physiol Rev 2020, 100, 695-724.

22. Broders-Bondon, F.; Nguyen Ho-Bouldoires, T.H.; Fernandez-Sanchez, M.E.; Farge, E. Mechanotransduction in tumor progression: The dark side of the force. J Cell Biol 2018, 217, 1571-1587.

23. Gupta, M.; Sarangi, B.R.; Deschamps, J.; Nematbakhsh, Y.; Callan-Jones, A.; Margadant, F.; Mège, R.M.; Lim, C.T.; Voituriez, R.; Ladoux, B. Adaptive rheology and ordering of cell cytoskeleton govern matrix rigidity sensing. Nat Commun 2015, 6, 7525.

24. Buracco, S.; Claydon, S.; Insall, R. Control of actin dynamics during cell motility. F1000Res 2019, 8, F1000 Faculty Rev-1977. 
27. Seetharaman, S.; Etienne-Manneville, S. Cytoskeletal crosstalk in cell migration. Trends Cell Biol 2020, 30, 720-735,

28. Miao, Z.; Ali, A.; Hu, L.; Zhao, F.; Yin, C.; Chen, C.; Yang, T.; Qian, A. Microtubule actin cross-linking factor 1, a novel potential target in cancer. Cancer Sci 2017, 108, 1953-1958.

29. Xu, H.; Dong, B.; Xiao, Q.; Sun, X.; Zhang, X.; Lyu, J.; Yang, Y.; Xu, L.; Bai, X.; Zhang, S.; et al. Three-Dimensional Inverse Opal Photonic Crystal Substrates toward Efficient Capture of Circulating Tumor Cells. ACS Appl Mater Interfaces 2017, 9, 30510-30518.

30. Chaudhuri, P.K.; Low, B.C.; Lim, C.T. Mechanobiology of Tumor Growth. Chem Rev 2018, 118, 6499-6515.

31. Davidson, A.J.; Wood, W. Unravelling the actin cytoskeleton: a new competitive edge? Trends Cell Biol 2016, $26,569-576$.

32. Gandalovicova, A.; Rosel, D.; Fernandes, M.; Vesely, P.; Heneberg, P.; Cermak, V.; Petruzelka, L.; Kumar, S.; Sanz-Moreno, V.; Brabek, J. Migrastatics-anti-metastatic and anti-invasion drugs: promises and challenges. Trends Cancer 2017, 3, 391-406.

33. Ong, M.S.; Deng, S.; Halim, C.E.; Cai, W.; Tan, T.Z.; Huang, R.Y.; Sethi, G.; Hooi, S.C.; Kumar, A.P.; Yap, C.T. Cytoskeletal proteins in cancer and intracellular Stress: a therapeutic perspective. Cancers (Basel) 2020, 12, 238.

34. Takanezawa, Y.; Nakamura, R.; Kojima, Y.; Sone, Y.; Uraguchi, S.; Kiyono, M. Cytochalasin E increased the sensitivity of human lung cancer A549 cells to bortezomib via inhibition of autophagy. Biochem Biophys Res Commun 2018, 498, 603-608.

35. Wang, C.; Lambert, C.; Hauser, M.; Deuschmann, A.; Zeilinger, C.; Rottner, K.; Stradal, T.E.B.; Stadler, M.; Skellam, E.J.; Cox, R.J. Diversely functionalised cytochalasins through mutasynthesis and semi-synthesis. Chemistry 2020, 26, 13578-13583.

36. Freitas, V.M.; Rangel, M.; Bisson, L.F.; Jaeger, R.G.; Machado-Santelli, G.M. The geodiamolide H, derived from Brazilian sponge Geodia corticostylifera, regulates actin cytoskeleton, migration and invasion of breast cancer cells cultured in threedimensional environment. J Cell Physiol 2008, 216, 583-594.

37. Pereira, J.H.; Petchprayoon, C.; Hoepker, A.C.; Moriarty, N.W.; Fink, S.J.; Cecere, G.; Paterson, I.; Adams, P.D.; Marriott, G. Structural and biochemical studies of actin in complex with synthetic macrolide tail analogues. ChemMedChem 2014, 9, 22862293.

38. Khanfar, M.A.; Youssef, D.T.; El Sayed, K.A. Semisynthetic latrunculin derivatives as inhibitors of metastatic breast cancer: biological evaluations, preliminary structure-activity relationship and molecular modeling studies. ChemMedChem 2010, 5, 274-285.

39. Konishi, H.; Kikuchi, S.; Ochiai, T.; Ikoma, H.; Kubota, T.; Ichikawa, D.; Fujiwara, H.; Okamoto, K.; Sakakura, C.; Sonoyama, T.; et al. Latrunculin a has a strong anticancer effect in a peritoneal dissemination model of human gastric cancer in mice. Anticancer Res 2009, 29, 2091-2097.

40. Sörensen, P.M.; Iacob, R.E.; Fritzsche, M.; Engen, J.R.; Brieher, W.M.; Charras, G.; Eggert, U.S. The natural product cucurbitacin E inhibits depolymerization of actin filaments. ACS Chem Biol 2012, 7, 1502-1508.

41. Zhang, T.; Li, J.; Dong, Y.; Zhai, D.; Lai, L.; Dai, F.; Deng, H.; Chen, Y.; Liu, M.; Yi, Z. Cucurbitacin E inhibits breast tumor metastasis by suppressing cell migration and invasion. Breast Cancer Res Treat 2012, 135, 445-458.

42. Jing, S.Y.; Wu, Z.D.; Zhang, T.H.; Zhang, J.; Wei, Z.Y. In vitro antitumor effect of cucurbitacin E on human lung cancer cell line and its molecular mechanism. Chin J Nat Med 2020, 18, 483-490.

43. Kunze, B.; Jansen, R.; Sasse, F.; Höfle, G.; Reichenbach, H. Chondramides A approximately D, new antifungal and cytostatic depsipeptides from Chondromyces crocatus (myxobacteria). Production, physico-chemical and biological properties. $J$ Antibiot (Tokyo) 1995, 48.

44. Menhofer, M.H.; Kubisch, R.; Schreiner, L.; Zorn, M.; Foerster, F.; Mueller, R.; Raedler, J.O.; Wagner, E.; Vollmar, A.M.; Zahler, S. The actin targeting compound Chondramide inhibits breast cancer metastasis via reduction of cellular contractility. PLoS One 2014, 9, e112542.

45. Holzinger, A. Jasplakinolide: an actin-specific reagent that promotes actin polymerization. Methods Mol Biol 2009, 586, 7187.

46. Karahalil, B.; Yardım-Akaydin, S.; Nacak Baytas, S. An overview of microtubule targeting agents for cancer therapy. Arh Hig Rada Toksikol 2019, 70, 160-172.

47. Dumontet, C.; Jordan, M.A. Microtubule-binding agents: a dynamic field of cancer therapeutics. Nat Rev Drug Discov 2010, 9, 790-803. Florian, S.; Mitchison, T.J. Anti-Microtubule Drugs. Methods Mol Biol 2016, 1413, 403-421, doi:10.1007/978-1-4939-3542-0_25. Kaul, R.; Risinger, A.L.; Mooberry, S.L. Microtubule-Targeting Drugs: More than Antimitotics. J Nat Prod 2019, 82, 680-685. Haider, K.; Rahaman, S.; Yar, M.S.; Kamal, A. Tubulin inhibitors as novel anticancer agents: an overview on patents (20132018). Expert Opin Ther Pat 2019, 29, 623-641, doi:10.1080/13543776.2019.1648433.

51. Zhao, Y.; Mu, X.; Du, G. Microtubule-stabilizing agents: New drug discovery and cancer therapy. Pharmacol Ther 2016, 162, 134-143. 
55. Gourmelon, C.; Bourien, H.; Augereau, P.; Patsouris, A.; Frenel, J.S.; Campone, M. Vinflunine for the treatment of breast cancer. Expert Opin Pharmacother 2016, 17, 1817-1823.

56. Capasso, A. Vinorelbine in cancer therapy. Curr Drug Targets 2012, 13, 1065-1071.

57. Xi, W.; Saw, T.B.; Delacour, D.; Lim, C.T.; Ladoux, B. Material approaches to active tissue mechanics. Nature Reviews Materials 2018, 4, 23-44.

58. Buxboim, A.; Ivanovska, I.L.; Discher, D.E. Matrix elasticity, cytoskeletal forces and physics of the nucleus: how deeply do cells 'feel' outside and in? J Cell Sci 2010, 123, 297-308.

59. Hsu, P.C.; Tian, B.; Yang, Y.L.; Wang, Y.C.; Liu, S.; Urisman, A.; Yang, C.T.; Xu, Z.; Jablons, D.M.; You, L. Cucurbitacin E inhibits the Yes-associated protein signaling pathway and suppresses brain metastasis of human non-small cell lung cancer in a murine model. Oncol Rep 2019, 42, 697-707.

60. Si, W.; Lyu, J.; Liu, Z.; Wang, C.; Huang, J.; Jiang, L.; Ma, T. Cucurbitacin E inhibits cellular proliferation and enhances the chemo-response in gastric cancer by suppressing AKt activation. J Cancer 2019, 10, 5843-5851.

61. Cao, Y.N.; Zheng, L.L.; Wang, D.; Liang, X.X.; Gao, F.; Zhou, X.L. Recent advances in microtubule-stabilizing agents. Eur J Med Chem 2018, 143, 806-828.

62. Alqahtani, F.Y.; Aleanizy, F.S.; El Tahir, E.; Alkahtani, H.M.; AlQuadeib, B.T. Paclitaxel. Profiles Drug Subst Excip Relat Methodol 2019, 44, 205-238.

63. Huang, F.Y.; Mei, W.L.; Li, Y.N.; Tan, G.H.; Dai, H.F.; Guo, J.L.; Wang, H.; Huang, Y.H.; Zhao, H.G.; Zhou, S.L.; et al. The antitumour activities induced by pegylated liposomal cytochalasin D in murine models. Eur J Cancer 2012, 48, $2260-2269$.

64. Sayed, K.A.; Khanfar, M.A.; Shallal, H.M.; Muralidharan, A.; Awate, B.; Youssef, D.T.; Liu, Y.; Zhou, Y.D.; Nagle, D.G.; Shah, G. Latrunculin A and its C-17-O-carbamates inhibit prostate tumor cell invasion and HIF-1 activation in breast tumor cells. J Nat Prod 2008, 71, 396-402. 